Березка Нина Николаевна

кандидат экономических наук, доцент кафедры экономики и менеджмента Института рекламы и связи с общественностью Новосибирского государственного педагогического университета

\section{РЫНОЧНО ОРИЕНТИРОВАННАЯ ДЕЯТЕЛЬНОСТЬ ОБРАЗОВАТЕЛЬНЫХ ОРГАНИЗАЦИЙ ВЫСШЕГО ОБРАЗОВАНИЯ}

\begin{abstract}
Аннотация:
В статье рассматриваются вопросы функционирования образовательных организаций высшего образования с позиции рыночного механизма, в том числе конкуренции среди вузов. Обозначены основные положения авторского подхода к изучению конкуренции на рынке образовательных услуг, в частности обобщены направления и круг исследовательских задач в соответствии с иелевыми ориентирами развития учебного учреждения.
\end{abstract}

Ключевые слова:

рынок, рыночный механизм, высшее образование маркетинг, конкуренция, конкурентные опасности, конкурентные стратегии, исследование конкуренции.
Beryozka Nina Nikolaevna

PhD in Economics, Assistant Professor, Economics and Management Department, Institute of Advertising and Public Relations, Novosibirsk State Pedagogical University

\section{MARKET-ORIENTED ACTIVITIES OF EDUCATIONAL INSTITUTIONS OF HIGHER EDUCATION}

Summary:

The article deals with the functioning of the educational institutions of higher education from the perspective of the market mechanism, including competition among universities. The paper outlines the basic principles of the author's approach to the study of competition on the educational services market, in particular it summarizes the direction and scope of research tasks in accordance with a target of the educational organization development.

Keywords:

market, market mechanism, higher education, marketing, competition, competitive danger, competitive strategies, research on competition.

Рыночные механизмы в образовательной среде (прежде всего в понимании востребованности результата обучения как особого специфического «продукта» образовательной деятельности) развиваются в условиях ее интенсивной трансформации и конкуренции, что является основополагающей положительной чертой рыночной модели. Кроме того, образовательные организации поставлены перед необходимостью разработки адаптационных, модернизационных, проектных решений в рамках внешней среды. Объектно - это сфера высшего образования, реформируемая и перенастраиваемая на протяжении длительного периода. Образовательные учреждения высшего образования функционируют в ситуации ухудшения социально-экономической обстановки, негативных изменений рынка труда, перераспределения расходов вследствие сокращения уровня доходов домохозяйств. Это в совокупности снижает потенциал готовности получения высшего образования, формирует у абитуриентов, их родителей, работодателей выраженно экономичный выбор варианта достижения образовательных целей, траектории обучения индивида.

Кроме того, существенны как целевые ориентиры, так и ограничения - требования, выдвигаемые со стороны регуляторов в системе образования, направленные на повышение качества образования, эффективности образовательных организаций, решение общегосударственных задач в системе науки и образования, в том числе вхождение российских университетов в мировой рейтинг. Также существенна дифференциация между столичными и региональными вузами, между учебными учреждениями с устойчивыми позициями преимущественного приема студентов на бюджетные места и вузами, которые работают в условиях платного приема на фоне сокращения числа бюджетных мест на отдельные направления подготовки или стремятся сохранить непрофильные факультеты и направления.

Министерство образования и науки РФ за последние 3-5 лет в 1,5-2,0 раза уменьшило количество бюджетных мест на популярные, эмоционально привлекательные направления подготовки экономистов, юристов, менеджеров [1]. Здесь мы имеем в виду субъективное, но исключительно положительное восприятие абитуриентами престижа образовательных программ по обучению профессиям финансиста, юриста, госслужащего и т. д. При этом сравнительно недавно стремительное возрастание числа вузов, занимающихся наиболее популярными группами направлений, воспринималось образовательным сообществом с пониманием. Сейчас мы констатируем малые контрольные цифры приема и многократное - в среднем в 3 раза - превышение объема платного приема по направлениям «экономика», «реклама и связи с общественностью», «юриспруден- 
ция». Это характеризует политику поистине хирургического вмешательства и резекции нефункционирующего, неизлечимого органа - вытеснения некачественных образовательных программ, их закрытия. Это вновь затрагивает непрофильные вузы, равно как и частные образовательные организации, многие из которых с трудом выдерживают критерии качества приема, реализации программ, а в итоге могут лишиться права на ведение образовательной деятельности. В 2014-2015 гг. в России было закрыто более 400 вузов, демонстрировавших недопустимо низкое качество обучения [2]. Такие вузы функционируют в условиях высоких конкурентных опасностей и угроз, где цена поражения целиком укладывается в терминологию ликвидационных стратегий. При этом стратегическая установка Минобрнауки, на наш взгляд, в полной мере адекватна сложившейся ситуации, когда рынку труда представлены посредственные по уровню подготовки менеджеры, экономисты, лингвисты, юристы, что отнюдь не способствует усилению экономики.

В рамках исследования мы изучили и обобщили основные положения теории маркетинга в образовании, которые можно сопоставить с этапами реформирования вузовской среды, построения системы, вполне отвечающей критериям рыночной деятельности:

- системный рыночно ориентированный подход, сама возможность платного обучения;

- открытость системы и создание среды сотрудничества между образовательными организациями, ориентация на существующие и будущие образовательные потребности;

- изменчивость, нестатичность фракторов окружающей среды, открывающая возможность проектирования стратегии, тактических мероприятий на уровне организации или их совокупности;

- развитие инфраструктуры образования, интеграция в международную образовательную среду;

- гибкость и вариативность программ обучения, поиск фрорм инструментального воздействия в целях удержания позиции образовательной организации среди аналогичных конкурирующих предприятий;

- возможность статистического наблюдения, систематизации, количественного и качественного анализа конъюнктурных и специализированных показателей состояния окружающей среды и операционной деятельности образовательных учреждений;

- фрактическая детерминированность стратегий функционирования образовательных организаций высшего образования - по географическому, территориальному охвату, по ценовым параметрам, в рамках политики образовательного продукта;

- возможность дифференцированных оценок по ряду значимых параметров результативности образовательной деятельности, лежащих в основе методологии конкурентоспособности организации, как соотношения цены и качества реализуемых направлений и профилей подготовки, а также программ дополнительного образования.

Данные ориентиры концептуально закреплены и соответствуют методологии маркетинга как деятельности по удовлетворению потребностей в условиях рынка. В теории маркетинга накоплен опыт решения самых сложных задач в сфере услуг, производства и сбыта товаров и услуг, информационно-аналитической работы по учету потребностей рынка, перспектив спроса. Широки междисциплинарные связи и существенны достижения по использованию на практике методического аппарата исследований в области маркетинга и конкурентных отношений. Кроме того, быстрое расширение отрасли услуг, прямое соотнесение сферы высшего образования и деятельности по оказанию образовательных услуг во многом предопределили актуальность концепции маркетинга образования [3].

Присущая сфере образования отраслевая специфика услуг вводит в качестве одного из критериев успеха рыночной деятельности взаимодействие, создание устойчивых отношений с потребителем, своеобразного повторяющегося спроса на обучение (продолжение обучения в магистратуре после завершения программы бакалавриата, традиционализм и обучение в конкретном вузе нескольких поколений семьи и т. д.), фрормируя в итоге имидж, бренд вуза, лояльность, доверие, признание. Впрочем, доверительные отношения и лояльность несут в себе и весьма ощутимый положительный финансовый результат для образовательной организации, поскольку самим потребителем зачастую и оплачиваются [4]. Однако они в полной мере характеризуют потенциал для большей ценовой дифференциации, группировки образовательных программ по критериям соотношения уровня цен и популярности.

По мере привнесения принципов рыночной экономики в систему социально-экономических отношений одновременно с реформированием высшей школы происходит содержательное наполнение механизма рыночно ориентированной, конкурентной деятельности. Среду высшего образования можно рассматривать через призму стандартизированного статистического наблюдения, прежде всего конъюнктурного анализа, освещающего разные стороны и элементы рыночной ситуации:

- наличие информации о конъюнктурообразующих фракторах (предложении, спросе, условиях рынка, в том числе рынка труда и механизма воспроизводства трудовых ресурсов и т. д.) в открытых источниках; 
- возможность ретроспективной и перспективной диагностики рынка, оценки его состояния, качественной и атрибутивной диагностики;

- наличие характеристик рынка, таких как масштаб (объем), основные пропорции, тенденции, показатели деловой активности;

- особенности и региональные различия рынка;

- наличие рисков;

- развитие конкурентной среды и возможность ее специализированного анализа;

- различие рыночных стратегий, реализуемых субъектами рынка, и др. [5].

На современном этапе рыночные ориентиры образовательной организации предполагают следующие установки в отношении ее деятельности.

- Предлагаются те образовательные программы, которые пользуются и будут пользоваться спросом на рынке. В соответствии с этим осуществляется перестройка потенциала и всей системы работы учреждения. При этом группу высокой опасности представляют те программы, на которые привлекаются не более чем 25-30 человек в год (одна или менее академических групп студентов) с понижающейся динамикой приема на платное обучение и при отсутствии бюджетного приема.

- Спектр образовательных программ достаточно широк и интенсивно обновляется с учетом требований экономики, общества. Соответственно, процессы и технологии оказания образовательных услуг гибкие и адаптационные.

- Предусмотрена ценовая дифференциация. Стоимость образовательных услуг формируется во многом под влиянием рынка и действующих на нем конкурентов, часто зависит от величины платежеспособного спроса.

- Активная коммуникационная деятельность приобретает целенаправленный характер, она ориентирована на конкретные целевые группы потребителей образовательных услуг. Комплексным характером коммуникация наделяется за счет использования возможностей сети Интернет: сайтов, социальных медиа, каталогов, поисковых систем [6].

- В организационной структуре образовательной организации реализуются отдельные функции маркетинга или их применение носит комплексный характер.

Система высшего образования в России - объект систематического реформирования, к настоящему времени не утратившая черт и проявлений саморегуляции как неотъемлемой черты рыночных отношений, среды конкуренции. Рынок образовательных услуг сложен и чрезвычайно разнообразен. В качестве объекта социологических, экономических, маркетинговых исследований в нем выступают сама образовательная организация и силы, входящие в ее микросреду внутреннюю среду маркетинга, в частности конкуренты, потребители; географические сегменты рынка (региональный, федеральный, национальный уровни); а также население или отдельная его группа как носитель демографических и социально-экономических фракторов макросреды, в том числе влияющих на образ жизни молодежи [7].

Исследования конкуренции в сфере высшего образования могут быть структурированы по следующим направлениям:

1. Количественные и качественные параметры спроса и предложения образовательных программ (границы, емкость рынка), окружающая маркетинговая среда, тенденции конъюнктуры рынка образовательных услуг, труда [8].

2. Конкурентоспособность программ подготовки, включая общеобразовательные, профессиональные, дидактические, экономические и другие сравнительные качественные показатели обучения. Определение конкурентного статуса организации, тесно связанного с имеющимися и развиваемыми конкурентными преимуществами организации [9].

3. Партнерские и посреднические отношения в образовательной среде, в том числе величина задействованных и потенциальных ресурсов, связи с промышленностью, уровень внедрения результатов НИР, НИОКР, объем финансирования научных исследований, грантов и т. д.

4. Стратегия и тактика деятельности образовательных учреждений, в том числе принятие решений о ценах, политике имиджа вуза, развитии программ магистерской подготовки, дополнительного образования.

5. В целом актуализация содержания, процессов и функций рыночно ориентированной деятельности образовательных организаций. Принятие принципов и методов управления учреждением на основе модели маркетинга, в том числе организационных и структурных изменений внутри учреждения.

Таким образом, круг задач исследований не затрагивает поэлементного анализа всех без исключения сущностных аспектов маркетинга услуг. Мы видим сфокусированными задачи относительно всего многообразия проявлений конъюнктуры рынка образовательных услуг. На наш взгляд, актуальна сама возможность применения арсенала специализированных маркетинговых средств оценки конкурентной позиции отдельного учебного учреждения. Кроме того, очевидны 
более фундаментальные управленческие задачи. Речь идет о проектировании на основе полученных данных действенных инструментов реализации стратегии и тактики образовательной организации в сложившейся рыночной ситуации.

\section{Ссылки:}

1. Мониторинг качества приема в вузы [Электронный ресурc]. URL: https://www.hse.ru/ege/stata (дата обращения: 17.03.2017)

2. Волков А., Ливанов Д. Зачем в России столько вузов // Ведомости. 2015. № 379.

3. Березин И.С. Мониторинг рынка образовательных услуг // Практический маркетинг. 2002. № 70. С. 6-7 ; Бухарова Г.Д., Старикова Л.Д. Маркетинг в образовании : учеб. пособие. М., 2015. 208 с. ; Красильникова Т.В., Шушаков А.А. Содержание процесса конкурентной среды рынка образовательных услуг // Современное коммуникационное пространство: анализ состояния и тенденции развития : материалы междунар. науч.-практ. конф. ; в 2 ч. / под ред. И.В. Архиповой. Новосибирск, 2016. Ч. 1. С. 132-135 ; Мамонтов С.А. Сфера образования как многоуровневая маркетинговая система // Маркетинг в России и за рубежом. 2001. № 5. С. 48-55; Панкрухин А.П. Философрские аспекты маркетингового подхода к образованию // Alma mater. 1997. № 1. С. 52-57 ; Его же. Маркетинг образовательных услуг в высшем и дополнительном образовании : учеб. пособие. М., 1995. 245 с.

4. Al-Dulaimi Z.Y.S. Education, educational services and their quality // Journal of Marketing Management. 2016. No. 4 (1). P. 58-66.

5. Статистика рынка товаров и услуг : учебник / И.К. Беляевский, Г.Д. Кулагина, А.В. Коротков и др. М., 1995. 432 с.

6. Поддячая Е.А. Присутствие вуза в социальных медиа: репутационный аспект // Современное коммуникационное пространство ... С. $128-135$.

7. Безродная Л.В. Роль системы образования в формировании образа жизни молодежи // Там же. С. 28-33.

8. Маркетинговые исследования рынка продуктов питания (региональный аспект) : учеб. пособие / Е.В. Смирнова, С.С. Фирсенко, Л.В. Спрыжкова и др. Красноярск, 2000. 216 с.

9. Юшкова Л.В. Система показателей исследования конкурентной среды отраслевого рынка // Финансовая экономика. 2013. № 5. C. $87-94$

\section{References:}

Al-Dulaimi, ZYS 2016, 'Education, educational services and their quality', Journal of Marketing Management, no. 4 (1), pp. 58-66, (in Russian).

Belyaevsky, IK, Kulagina, GD \& Korotkov, AV (et al.) 1995, Statistics of the goods and services market, textbook, Moscow, 432 p., (in Russian).

Berezin, IS 2002, 'Monitoring the market of educational services', Prakticheskiy marketing, no. 70, pp. 6-7, (in Russian).

Bezrodnaya, LV \& Arkhipova, IV (ed.) 2015, 'The role of the education system in forming the way of life of young people', Sovremennoye kommunikatsionnoye prostranstvo: analiz sostoyaniya i tendentsii razvitiya: materialy mezhdunar. nauch. -prakt. konf., in 2 parts, Novosibirsk, Part 1, pp. 28-33, (in Russian).

Bukharova, GD \& Starikova, LD 2015, Marketing in education, study guide, 208 p., Moscow, (in Russian).

Krasilnikova, TV, Shushakov, AA \& Arkhipova, IV (ed.) 2016, 'The content of the competitive environment process on the market of educational services', Sovremennoye kommunikatsionnoye prostranstvo: analiz sostoyaniya i tendentsii razvitiya: materialy mezhdunar. nauch.-prakt. konf., in 2 parts, Novosibirsk, Part 1, pp. 132-135, (in Russian).

Mamontov, SA 2001, 'The sphere of education as a multilevel marketing system', Marketing v Rossii i za rubezhom, no. 5 , pp. 48-55, (in Russian).

Pankrukhin, AP 1995, Marketing of educational services in higher and continuing education, study guide, Moscow, 245 p., (in Russian).

Pankrukhin, AP 1997, 'Philosophical aspects of the marketing approach to education', Alma mater, no. 1, pp. 52-57, (in Russian)

Poddyachaya, EA \& Arkhipova, IV (ed.) 2015, 'The presence of the university in social media: reputation aspect', Sovremennoye kommunikatsionnoye prostranstvo: analiz sostoyaniya i tendentsii razvitiya: materialy mezhdunar. nauch. -prakt. konf., in 2 parts, Novosibirsk, Part 1, pp. 128-135, (in Russian).

Smirnova, EV, Firsenko, SS \& Spryzhkova, LV (et al.) 2000, Marketing research of the food market (regional aspect), study guide, Krasnoyarsk, 216 p., (in Russian).

Volkov, A \& Livanov, D 2015, 'Why do so many universities in Russia', Vedomosti, no. 379, (in Russian).

Yushkova, LV 2013, 'System of research indicators for the competitive environment of the branch market', Finansovaya ekonomika, no. 5, pp. 87-94, (in Russian). 